\title{
FREE TRIAL OF RISK ASSESSMENT SOFTWARE
}

Previser Corporation, a US provider of oral disease and risk assessment technology, has reached a licensing agreement with Oral Health Innovations of Birmingham to market Previser technology to dentists in the UK. OHI will launch Previser this month (June). Discussions are also underway with Primary Care Trusts on how technology can be used within NHS dentistry. A percentage of the profits of $\mathrm{OHI}$ will be contributed to the Oral and Dental Research Trust and to a research fellowship at Birmingham University.

The PreViser software can be downloaded from www.previser.co.uk and used free for a 30 day trial period.

Reader response number 59

\section{SOFT PICKS}

There is now a softer alternative to wooden toothpicks for removing food from between teeth.

Soft Picks have already become one of the most popular products in the Sunstar GUM range. Soft Picks have tiny soft rubber bristles which remove plaque and food particles from between the teeth and can even be used by those with the most sensitive gums. They are clinically proven to remove $25 \%$ of plaque and reduce interdental bleeding to lessen gingivitis by 33\% over six weeks.

The flexible rubber bristles can be used to stimulate the gums and are also gentle and safe to use on sensitive gums. They slide between teeth to help safely remove plaque and food particles thanks to the tapered design which fits into small interdental

\section{SENSITIVE SENSORS}

$\mathrm{X}$-rays are needed on so many occasions that it is important they are quick and easy to perform. Have you ever considered the advantages of digital X-rays?

DMDS are able to supply you with the latest digital X-ray equipment providing you with ultra thin sensors for even more accurate images at the very highest resolution.

The sensors are extremely thin for patient comfort and are provided in familiar sizes similar to traditional Xray films. You will certainly notice the difference in the clarity of the image. Normal X-rays provide you with 15 line pairs whereas DMDS digital Xray system's MegaPixel Dentistry provides you with 22 line pairs and

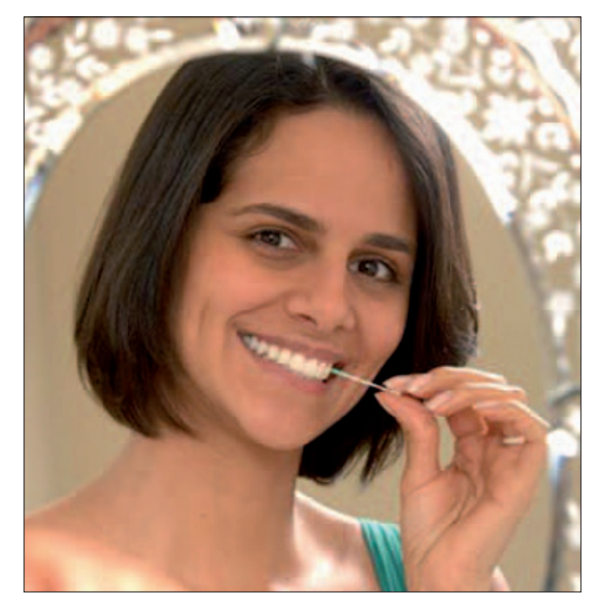

spaces and works with appliances such as bridges, implants and orthodontics.

A hygienic carrying case containing 40 Soft Picks can be slipped in a pocket or bag for discreet use on-the-go.

Reader response number 60

over $2 \mathrm{~m}$ pixels, which is $45 \%$ higher than films.

There will not be any re-takes as the film cannot be over or under exposed allowing absolutely precise instant images every time. You will be able to view the images immediately on your screen.

Reader response number 61

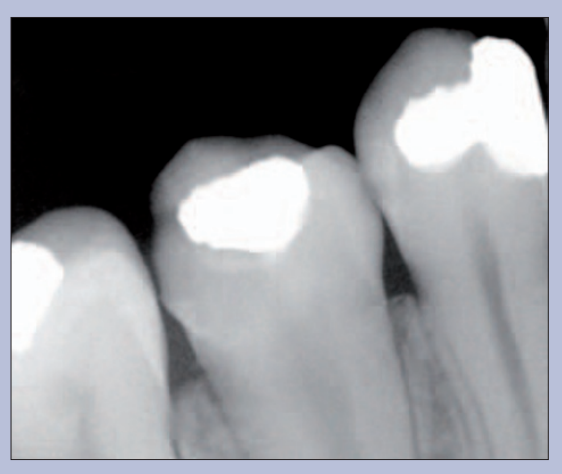

